\title{
Effect of combined treatment with progesterone and tamoxifen on the growth and apoptosis of human ovarian cancer cells
}

\author{
JI-YOUNG LEE ${ }^{3}$, JONG-YEON SHIN ${ }^{4}$, HYUN-SEOK KIM ${ }^{5}$, JEE-IN HEO ${ }^{1,2}$, YOON-JUNG KHO ${ }^{2}$, \\ HONG-JUN KANG ${ }^{6}$, SEONG-HOON PARK $^{1,5}$ and JAE-YONG LEE ${ }^{1,2}$
}

\begin{abstract}
${ }^{1}$ Department of Biochemistry and ${ }^{2}$ Institute of Natural Medicine, College of Medicine, Hallym University, Chuncheon, Gangwon-do 200-702, Republic of Korea; ${ }^{3}$ Department of Obstetrics and Gynecology, Sisters of Charity Hospital, State University of New York at Buffalo, Buffalo, NY 14214, USA; ${ }^{4}$ Genomic Medicine Institute, Medical Research Center, Seoul National University, Seoul, Republic of Korea; ${ }^{5}$ Molecular Radiation Oncology, Radiation Oncology Branch, Center for Cancer Research, NCI, NIH, Bethesda, MD 20892; ${ }^{6}$ Genetic Disease Research Section, NIDDK, National Institutes of Health, Building 10, Room 9D11, Bethesda, MD 20892, USA
\end{abstract}

Received June 9, 2011; Accepted July 28, 2011

DOI: $10.3892 /$ or.2011.1460

\begin{abstract}
Progesterone has a potential protective effect against ovarian carcinoma induced by estrogen. Progesterone is also known to cause apoptosis while tamoxifen induces growth arrest. Therefore, we attempted to determine whether combined treatment with progesterone and tamoxifen has a synergistic effect on anti-cancer activity. Although progesterone is known to cause apoptosis while tamoxifen induces growth arrest in many cancer cells, the detailed action of progesterone and tamoxifen and the anticancer effect of combined treatment have not been tested in ovarian cancer cells. Therefore, we tested the growth and apoptosis activity of progesterone and tamoxifen and the anticancer effect of combined treatment of progesterone and tamoxifen in ovarian cancer cells. Ovarian cancer cells, PA-1, were treated with progesterone, tamoxifen, or a combination of progesterone and tamoxifen. The anti-cancer effects were investigated by use of flow cytometry, terminal deoxynucleotidyl transferase dUTP nick end labeling (TUNEL) assay, DNA fragmentation analysis, and Western blot analysis. We found that $100 \mu \mathrm{M}$ progesterone induced typical apoptosis in PA-1 cells. Treatment of PA-1 cells with $10 \mu \mathrm{M}$ tamoxifen resulted in an increase in the levels of p21, p27, p16 and phospho-pRb, indicating typical $\mathrm{G}_{1}$ arrest. Co-treatment of PA-1 cells with $100 \mu \mathrm{M}$ progesterone and $10 \mu \mathrm{M}$ tamoxifen resulted in typical apoptosis, similar to that induced by treatment with $100 \mu \mathrm{M}$ progesterone alone. These results indicate that progesterone caused apoptosis and tamoxifen induced $\mathrm{G}_{1}$ arrest. Combined treatment with tamoxifen and progesterone caused apoptosis
\end{abstract}

Correspondence to: Dr Jae-Yong Lee, Department of Biochemistry, College of Medicine, Hallym University, 1 Okcheon-dong, Chuncheon, Gangwon-do 200-702, Republic of Korea

E-mail: jyolee@hallym.ac.kr

Key words: ovarian cancer cell line, progesterone, tamoxifen, apoptosis, growth arrest similar to that induced by treatment with progesterone alone and had no additional anti-cancer effect in ovarian cancer cells.

\section{Introduction}

Ovarian carcinoma is one of the most common fatal gynecologic malignancies and is characterized by an insidious onset and a lack of early specific symptoms. About two-thirds of patients with ovarian carcinoma usually present with advanced ovarian carcinoma and have widespread tumor dissemination. Unfortunately, the most effective strategy for the management of ovarian carcinoma is yet to be determined. Although Taxol and platinum-based combination chemotherapy is a standard treatment for ovarian carcinoma and has achieved a high response rate, its success is limited by the development of drug resistance (1). Therefore, it is important to explore alternative treatment modalities that have favorable cost benefit ratios in terms of toxicity and do not lead to the development of drug resistance or disease relapse.

It has been reported that estrogen and progesterone are involved in the etiology and long-term survival of patients with ovarian carcinoma. In 1963, Long and Evans (2) suggested for the first time that ovarian carcinoma might be sensitive to hormones. According to their report, the use of diethylstilbestrol in 14 patients with advanced ovarian carcinoma led to a partial response in 4 (28\%) patients. The incidence of ovarian carcinoma is increased among women after menopause because of lower levels of sex steroids. Estrogen replacement therapy in postmenopausal women does not reduce the risk of ovarian carcinoma. However, the risk may be reduced by use of combination-type oral contraceptives, which contain estrogen and a high dose of progesterone. Recent studies have reported the presence of estrogen, progesterone, and androgen receptors in varying concentrations and combinations in ovarian carcinoma (3). According to the results of many studies, although estrogen is proposed to facilitate the induction of ovarian carcinoma, progesterone has a potential protective effect $(4,5)$. Progesterone has strong effects on 
human hormone-responsive endometrial and breast cancers. It has also been reported that progesterone significantly inhibits cell proliferation and reduces the risk of ovarian carcinoma (6). In particular, because progesterone has been reported to have antiproliferative and apoptotic effects on ovarian cancer cell lines, progesterone has been widely used in the clinical treatment of ovarian carcinoma. Van der Vange et al (7) reported that the response rate was approximately $7 \%$ in a series with an adequate number of patients and response criteria. In addition to progesterone, tamoxifen, which is a competitive estrogen antagonist, has been successfully used in the management of early and advanced breast cancer. The clinical activity of anti-estrogens in ovarian carcinoma was first reported by Myers et al (8). The reported response rates to tamoxifen were between 0 and $28 \%$, and the overall response rate was approximately $8 \%$. Although Marth et al suggested a better response for endometrioid adenocarcinomas of the ovary, a literature review revealed no apparent differences in histological subtype, grade of tumor, or hormone receptor values between responders and non-responders and no correlation between response rate and the presence of estrogen or progesterone receptors in the tumors were evident (9-11). However, the estrogen receptor-negative/progesterone receptor-positive phenotype predicts favorable tumor biology and long term survival, probably reflecting the functional effects on tumor proliferation, differentiation, and apoptosis (12). Tamoxifen causes cell cycle arrest $\left(\mathrm{G}_{0} / \mathrm{G}_{1}\right.$ arrest) with up-regulation of both p21 and p27 levels in susceptible estrogen-receptor positive breast cancer cells (13). The exact molecular mechanisms of apoptosis or growth arrest of ovarian cancer cells induced by progesterone and tamoxifen are not clear. In addition, the effect of combined treatment of progesterone and tamoxifen has not been tested.

In this study, the molecular mechanisms of apoptosis and growth arrest of ovarian cancer cells induced by progesterone and tamoxifen were investigated. In addition, the effect of combined treatment of progesterone and tamoxifen was tested since combined treatment seems to have synergistic effects.

\section{Materials and methods}

Cell lines and cell cultures. PA-1, a human ovarian cancer cell line with wild-type p53, was obtained from ATCC (American Type Culture Collection, Manassas, VA, USA). Cells were cultured in Dulbecco's modified essential medium (DMEM, Gibco-BRL, NY) supplemented with $10 \%$ fetal bovine serum (FBS; Life Technologies, Inc.), streptomycin $(100 \mu \mathrm{g} / \mathrm{ml})$, and penicillin $\mathrm{G}(100 \mathrm{IU} / \mathrm{ml})$, and maintained at $37^{\circ} \mathrm{C}$ in a humidified incubator with $5 \% \mathrm{CO}_{2}$.

$R T-P C R$. Total-RNA was isolated from $2 \times 10^{6}$ cells using RNA Plus $^{\text {TM }}$ (Quantum Biotechnologies, Inc., CA). cDNA was synthesized by incubation at $52^{\circ} \mathrm{C}$ for $20 \mathrm{~min}$ in a $20-\mu 1$ reaction volume containing RNA (100 ng), $10 \mathrm{mM}$ deoxynucleotide triphosphates (Boehringer Mannhein), 10X reaction buffer (provided by Takara Shuzo Co., Japan) and Avian Myeloblastosis Virus (AMV) reverse transcriptase (Takara). Primers for hormone receptor gene were designed that amplify mRNAs between exons 7 and 8 of the estrogen receptor gene (5'-GCACCCTGAAGTCTCTGGAA-3', 5'-TGGCTA
AAGTGGTGCATGAT-3'), exons 3 and 4 of progesterone receptor mRNA (5'-TGTCAGGCTGGCATGGTCCTTGG-3', 5'-GACGGGTGACTGCAGAAACATCC-3'). The PCR reaction was performed as follows; incubation at $95^{\circ} \mathrm{C}$ for $8 \mathrm{~min}$ followed by 40 cycles of reaction (denaturation at $95^{\circ} \mathrm{C}$ for $1 \mathrm{~min}$, annealing at different temperature for $1 \mathrm{~min}$, extension at $72^{\circ} \mathrm{C}$ for $1 \mathrm{~min}$ ), and a final extension at $72^{\circ} \mathrm{C}$ for $10 \mathrm{~min}$. Annealing temperatures for the estrogen receptor and progesterone receptor were 55 and $65^{\circ} \mathrm{C}$, respectively. The amplified PCR products were resolved by electrophoresis on $1 \%$ agarose gel and visualized by ethidium bromide staining.

Treatment of PA-1 cells with tamoxifen, progesterone, or both. Progesterone (Sigma, St. Louis, MO) and tamoxifen (Sigma) were dissolved in ethanol and kept at $4^{\circ} \mathrm{C}$ until use. Cells were plated and medium was changed to DMEM with $10 \%$ charcoalstripped FBS and antibiotics (streptomycin and penicillin G) to deplete medium steroid hormones and estrogenic compounds for the remainder of the assay period. After $48 \mathrm{~h}$, cultures were replenished with fresh charcoal-stripped DMEM, and then progesterone, tamoxifen, or both drugs were added to each dish.

Methyl thiazole tetrazolium (MTT) assay. Cells were seeded in 96-well plates at a density of $2 \times 10^{6}$ cells/well and incubated for $24 \mathrm{~h}$. After treatment of drugs, the cell growth was assessed by staining with MTT dye at $37^{\circ} \mathrm{C}$ for $2 \mathrm{~h}$. The staining medium was then replaced by phosphate-buffered saline (PBS) with $2.5 \%$ of protamin sulfate stock solution (Sigma), and the plates were incubated at $4^{\circ} \mathrm{C}$ overnight. The formazan was extracted with $250 \mu \mathrm{l}$ of dimethyl sulfoxide (DMSO, 10\%, Sigma) at room temperature for $4 \mathrm{~h}$. Then $150 \mu \mathrm{l}$ of the extract was transferred to a flat-bottomed 96-well plate for reading the absorbance at $570 \mathrm{~nm}$ in a microplate reader (Dynatech, UK).

Cell cycle analysis. Cells were harvested by trypsinization at $0,12,24$, and $48 \mathrm{~h}$ after drug treatment, collected gently, and resuspended in $2 \mathrm{ml}$ of PBS. Cells were then fixed by adding gradually $5 \mathrm{ml}$ of $95 \%$ ethanol with vortexing. After incubation at room temperature for $30 \mathrm{~min}$, cells were stored at $4^{\circ} \mathrm{C}$. Cells were then collected by centrifugation and stained by adding $1 \mathrm{ml}$ of $50 \mu \mathrm{g} / \mathrm{ml}$ propidium iodide solution (Sigma). RNase A (Sigma) was then added at a final concentration of $100 \mu \mathrm{g} / \mathrm{ml}$ and samples were incubated at room temperature for $30 \mathrm{~min}$. The DNA contents of the cells were analyzed by a Becton-Dickinson FACScan flow cytometer.

TUNEL assay: terminal deoxynucleotidyl transferasemediated dUTP nick end labeling. PA-1 cells were attached to Poly-Prep slides (Sigma) and treated with progesterone $100 \mu \mathrm{M}$ for $48 \mathrm{~h}$. The cells were fixed with $10 \%$ buffered formalin and permeabilized by immersing the slides in $0.2 \%$ Triton X-100 solution. After the cells were washed in PBS, the cells were incubated in equilibrium buffer $(200 \mathrm{mM}$ potassium cacodylated, $\mathrm{pH}$ 6.6, $25 \mathrm{mM}$ Tris- $\mathrm{HCl}, \mathrm{pH}$ 6.6, 0.2 mM DTT, $0.25 \mathrm{mg} / \mathrm{ml} \mathrm{BSA}$ and $2.5 \mathrm{mM}$ cobalt chloride) containing biotinylated nucleotide mix and 25 units of terminal deoxynucleotidyl transferase $(\mathrm{TdT})$ at $37^{\circ} \mathrm{C}$ for $1 \mathrm{~h}$. The reaction was stopped by immersing the slides in $2 \mathrm{X} \mathrm{SSC}(0.3 \mathrm{M} \mathrm{NaCl}$ and $30 \mathrm{mM}$ sodium citrate, $\mathrm{pH}$ 7.0). The cells on slides were incubated in $0.3 \%$ hydrogen peroxide and then with strepta- 


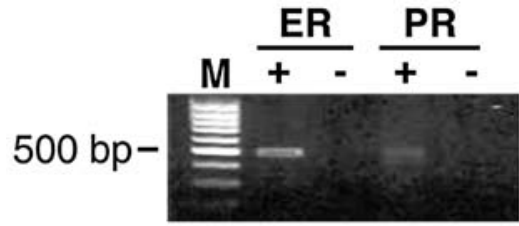

Figure 1. Expression of estrogen and progesterone receptors in ovarian cancer PA-1 cells. The expression of estrogen and progesterone receptors in ovarian cancer PA-1 cells was examined through RT-PCR. RT (-) indicates the absence of reverse transcriptase. The sizes of RT-PCR products for estrogen and progesterone receptors were 470 and 460 bp. ER, estrogen receptor; PR, progesterone receptor.

vidin horseradish-peroxidase (HRP) diluted in PBS. The cells were incubated with diaminobenzidine (DAB) components, rinsed several times with deionized water, and mounted in an aqueous or permanent mounting medium. Each slide was observed under a fluorescence microscope and photographs were taken at appropriate magnification. All batches of experiments were repeated at least three times.

Analysis of DNA fragmentation. Drug treated-cells were washed twice with PBS and resuspended in $25 \mu 1$ PBS. Cells were lysed by the addition of $25 \mu \mathrm{l}$ lysis buffer $(60 \mathrm{mM}$ Tris, $\mathrm{pH} 7.4,50 \mathrm{mM}$ ethylene diamine tetraacetic acid, and 1.6\% sodium lauryl sarcosine) containing proteinase $\mathrm{K}$, and incubation was carried out at $50^{\circ} \mathrm{C}$ for $3 \mathrm{~h}$, and digestion with $200 \mu \mathrm{g} / \mathrm{ml}$ DNase-free RNase A for an additional $20 \mathrm{~min}$. DNA from the cell lysates was then analyzed on a $2 \%$ agarose gel containing ethidium bromide, and visualized and photographed under ultraviolet light. All batches of experiments were repeated at least three times.

Detection of apoptosis-related proteins and cyclin-dependent kinase inhibitors. Cells were lysed in lysis buffer $(10 \mathrm{mM}$ Tris- $\mathrm{HCl}$, pH 7.4, 100 mM NaCl, 5 mM EDTA, 10\% glycerol, and 1\% NP-40, $0.1 \mathrm{mM}$ PMSF, $10 \mu \mathrm{g} / \mathrm{ml}$ each leupeptin, aprotinin, and pepstatin A). Equal amounts of proteins were subjected to sodium dodecyl sulfate-polyacrylamide gel electrophoresis (SDS-PAGE) and transferred to PVDF membranes (Millipore, USA). PVDF membranes were incubated with primary antibodies and then with horseradish peroxidaseconjugated secondary antibodies. The resulting bands were visualized by ECL system (Amersham Biosciences).

Primary antibodies used in this study were anti-caspase-3, anti-poly (ADP-ribose) polymerase (PARP), anti-cytochrome c, anti-BAX, anti-BCL-2, anti-p53, anti-p21, anti-p27, anti-p16 and anti-Rb. All batches of experiments were repeated at least three times.

Subcellular fractionation. Cell pellets were resuspended in sucrose-supplemented cell extract buffer (300 mM sucrose, $10 \mathrm{mM}$ HEPES, pH 7.4, $50 \mathrm{mM} \mathrm{KCl,} 5 \mathrm{mM}$ EGTA, $5 \mathrm{mM}$ $\mathrm{MgCl}_{2}, 1 \mathrm{mM}$ DTT, and protease inhibitor mixture). The cells were homogenized on ice with a dounce homogenizer. Unbroken cells and nuclei were removed by centrifugation at $2,000 \mathrm{x} \mathrm{g}$ at $4^{\circ} \mathrm{C}$ for $10 \mathrm{~min}$. The post-nuclear supernatant was further collected at $10,000 \mathrm{x}$ g for at $4^{\circ} \mathrm{C} 10 \mathrm{~min}$. The purity of the mitochondria fraction was determined by the absence of cytosolic $\beta$-actin using Western blot analyses. The supernatant
A

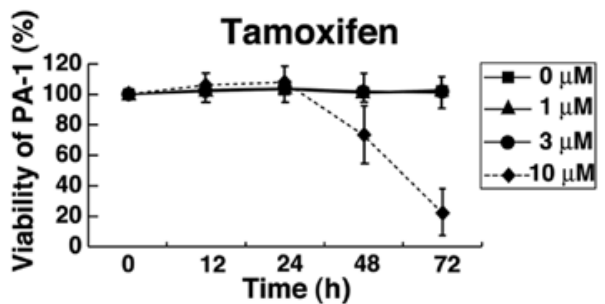

B

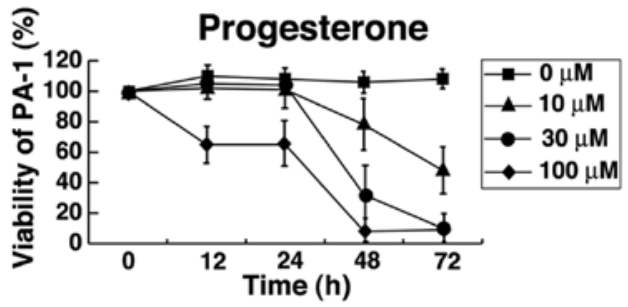

C

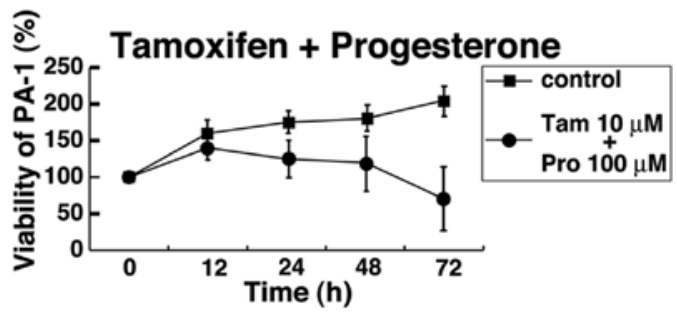

Figure 2. Viability of ovarian cancer PA-1 cells when treated with tamoxifen, progesterone or both. (A) Tamoxifen $(0,1,3$ and $10 \mu \mathrm{M})$, (B) progesterone $(0,10,30$ and $100 \mu \mathrm{M})$ or $(\mathrm{C})$ both drugs $(10 \mu \mathrm{M}$ tamoxifen and $100 \mu \mathrm{M}$ progesterone) were added to PA-1 cells incubated in charcoal-stripped DMEM. After incubation for indicated periods $(0,12,24,36,48$ and $72 \mathrm{~h})$, cell growth was assessed by staining with methyl thiazole tetrazolium (MTT) dye as described in 'Materials and methods'. Viability (\%) was defined as the percent of the absorbance of the drug-treated cells over that of control cells. All batches of experiments were repeated at least three times and average values with standard deviations were plotted.

was further ultracentrifuged at $14,000 \mathrm{x}$ g for $10 \mathrm{~min}$ and then filtered by passing through a $0.22-\mu \mathrm{m}$ filter (Millipore) to generate purified cytosolic fraction.

\section{Results}

mRNA expression of estrogen and progesterone receptors in $P A-1$ cells. Before the effects of progesterone and tamoxifen were tested, the expression of estrogen and progesterone receptors in PA-1 cells, which have wild type p53, was first assessed by RT-PCR. The expression of progesterone and estrogen receptor mRNAs in PA-1 cells was evident when compared with the control samples without reverse transcriptase (Fig. 1). The estrogen receptor mRNA amplicon was 470 base pairs (bp), and the progesterone receptor mRNA amplicon was 460 bp.

Effects of progesterone and tamoxifen on cell proliferation and viability. After treatment with progesterone, tamoxifen, or both hormones, the viability of ovarian cancer cells was evaluated by using the MTT assay. Progesterone was added at final concentrations of 10,30 or $100 \mu \mathrm{M}$ to PA-1 cells growing in DMEM with charcoal-stripped FBS. The PA-1 cells were 
Tamoxifen

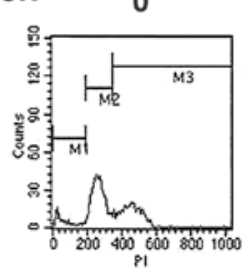

Marker

\begin{tabular}{lr}
\hline M1 & 8.61 \\
M2 & 58.56 \\
M3 & 36.91
\end{tabular}

Progesterone

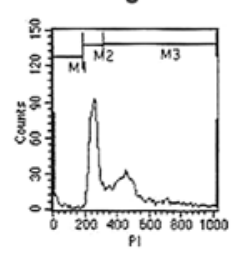

Marker
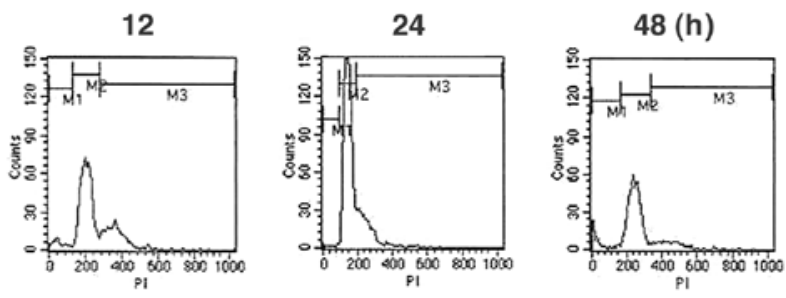

$\%$ Gated

4.00
70.64
25.40

12

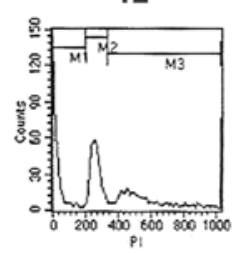

$\%$ Gated
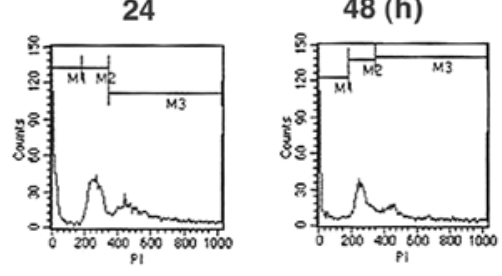

$\begin{array}{ll}\text { M1 } & 10.16 \\ \text { M2 } & 45.17\end{array}$

M3 $\quad 44.76$

22.79
32.00

32.00
26.33

32.35
29.53

29.53
38.18

48.57

24.26

27.31

\section{Tamoxifen + Progesterone}
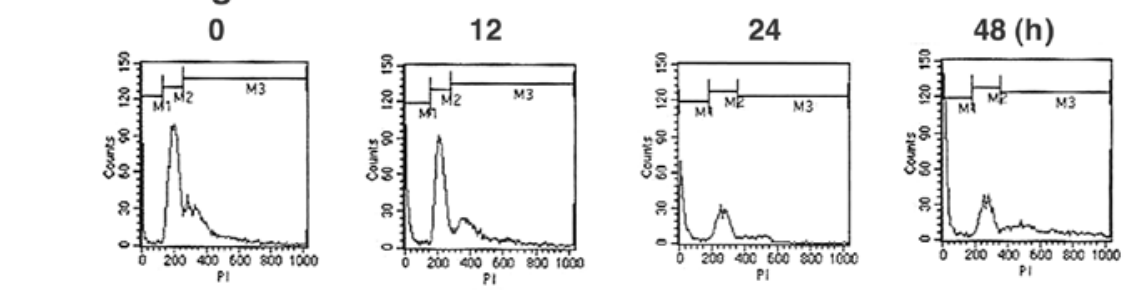

Marker

$\%$ Gated

\begin{tabular}{lrrrr}
\cline { 2 - 2 } & 6.18 & 19.75 & 38.09 & 49.73 \\
M2 & 58.94 & 49.42 & 49.78 & 22.28 \\
M3 & 35.09 & 30.95 & 12.19 & 28.03
\end{tabular}

Figure 3. Cell cycle analysis of ovarian cancer PA-1 cells treated with tamoxifen, progesterone and both. PA- 1 cells were treated with $10 \mu \mathrm{M}$ tamoxifen, $100 \mu \mathrm{M}$ progesterone, or both drugs (tamoxifen $10 \mu \mathrm{M}$ and progesterone $100 \mu \mathrm{M}$ ), respectively, for $0,12,24$ and $48 \mathrm{~h}$. Cells were harvested and stained with propidium iodide as described in 'Materials and methods'. The DNA content of the cells was analyzed and plotted using a Becton-Dickinson FACScan (Caliber) flow cytometer. Percent populations of M1, M2 and M3 were also calculated and summarized. M1 represents the population of $\mathrm{G}_{0}$ apoptotic cells. M2 represents the population of $G_{1}$ phase cells. $M 3$ represents the population of $S, G_{2}$ and $M$ phase cells.

incubated for $0,12,24,48$ or $72 \mathrm{~h}$. The control cells were not treated with progesterone. Treatment with $10 \mu \mathrm{M}$ progesterone slightly inhibited cell growth as compared to the control cells. Significant cell growth inhibition was observed at $100 \mu \mathrm{M}$ of progesterone at $48 \mathrm{~h}$ of incubation (Fig. 2B).

Similarly, PA-1 cells were treated with 1,3 or $10 \mu \mathrm{M}$ tamoxifen for $0,12,24,48$ or $72 \mathrm{~h}$, and the number of the viable cells was counted. As was observed with progesterone, the effects of tamoxifen were dependent on concentration. Treatment with 1 or $3 \mu \mathrm{M}$ tamoxifen had little effect, but $10 \mu \mathrm{M}$ of tamoxifen significantly decreased cell viability at $48 \mathrm{~h}$ (Fig. 2A). The effective concentrations of progesterone and tamoxifen for inhibition of cell growth were 100 and $10 \mu \mathrm{M}$, respectively, and these concentrations were used for subsequent experiments. Co-treatment with $10 \mu \mathrm{M}$ tamoxifen and $100 \mu \mathrm{M}$ progesterone resulted in less pronounced inhibition of growth than observed with either progesterone or tamoxifen treatment alone (Fig. 2C).
Cell cycle analysis. As $100 \mu \mathrm{M}$ progesterone and $10 \mu \mathrm{M}$ tamoxifen were most effective in inhibiting cell proliferation, these concentrations were used for cell cycle analysis. The nuclear DNA content of individual cells was analyzed by flow cytometry after treatment with $100 \mu \mathrm{M}$ progesterone, $10 \mu \mathrm{M}$ tamoxifen, or both to evaluate cell viability and cell cycle distribution. The peak representing cells in sub- $G_{0}$ phase was evaluated after $0,12,24$ and $48 \mathrm{~h}$ of incubation (Fig. 3). The number of cells in sub- $\mathrm{G}_{0}$ (M1 phase) increased markedly after treatment with $100 \mu \mathrm{M}$ progesterone as incubation time increased, whereas the fraction of cells in S-phase (M3 phase) decreased. When PA-1 cells were treated with $10 \mu \mathrm{M}$ tamoxifen, most cells were in the $\mathrm{G}_{1}$ stage of the cell cycle (M2 phase). After co-treatment with tamoxifen and progesterone, the number of cells in the sub- $\mathrm{G}_{0}$ stage increased markedly as incubation time increased, but the fraction of cells in S-phase decreased. These results suggest that treatment with progesterone and co-treatment with progesterone 
A
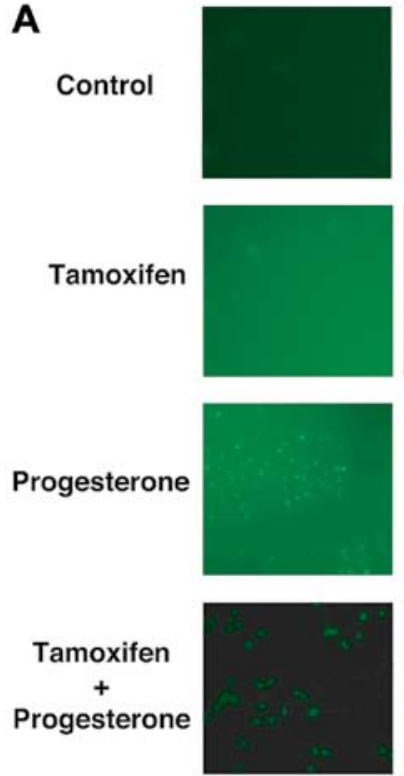

TUNEL
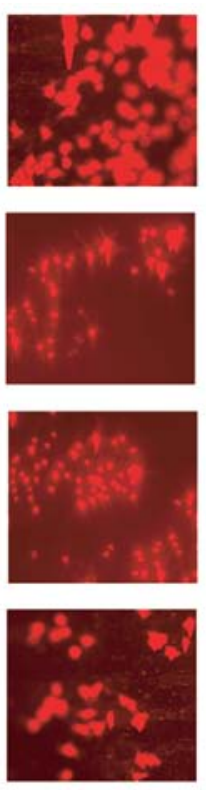

Pl
B

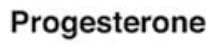

M 0122448 (h)
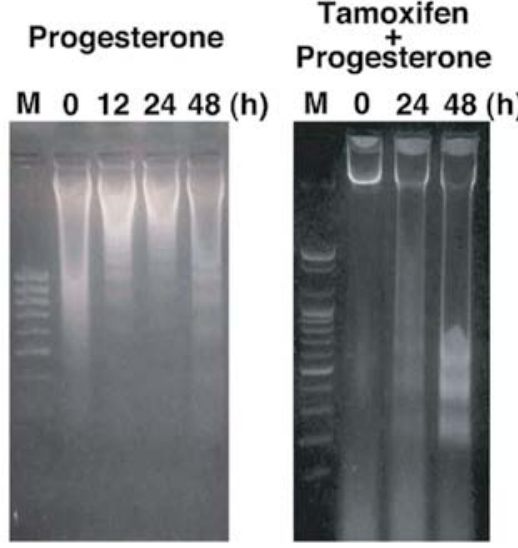

Figure 4. Apoptosis analysis of PA-1 cells treated with tamoxifen and progesterone. (A) The TUNEL assay was performed in PA-1 cells treated with tamoxifen and progesterone as described in 'Materials and methods'. PA-1 cells were attached to Poly-Prep slides and treated with tamoxifen (10 $\mu$ M), progesterone $(100 \mu \mathrm{M})$, or both $(10 \mu \mathrm{M}$ tamoxifen and $100 \mu \mathrm{M}$ progesterone) for $0,12,24$ and $48 \mathrm{~h}$. The cells were then incubated in equilibrium buffer containing biotinylated nucleotide mix and terminal deoxynucleotidyl transferase (TdT). The cells on slides were incubated with streptavidin horseradish-peroxidase (HRP) and diaminobenzidine (DAB) and observed under a fluorescence microscope. Images were captured at appropriate magnification. (B) DNA fragmentation analysis was performed to confirm progesterone-induced apoptosis of PA-1 cells. Progesterone or tamoxifen/progesterone-treated cells were lysed using lysis buffer containing proteinase $\mathrm{K}$ and digested with DNase-free RNase A for 20 min. DNA from the cell lysates was then analyzed on a $2 \%$ agarose gel containing ethidium bromide, and visualized and photographed under ultraviolet light.

and tamoxifen caused apoptosis because of the increased cell population in the sub- $G_{0}$ phase. Treatment with tamoxifen resulted in $\mathrm{G}_{1}$ arrest because of the increased number of cells in the $\mathrm{G}_{1}$ phase.

Analysis of progesterone-induced apoptosis. To confirm progesterone-induced apoptosis in PA-1 cells, terminal deoxynucleotidyl transferase dUTP nick end labeling (TUNEL) assay, DNA fragmentation analysis, and Western blot analysis of apoptotic markers were performed. After treatment with $100 \mu \mathrm{M}$ progesterone, $10 \mu \mathrm{M}$ tamoxifen, or both for $48 \mathrm{~h}$, the number of apoptotic cells with fragmented DNA were quantitatively determined by TUNEL assay. Apoptotic cells (fluorescent cells) were detected by use of a fluorescence microscope (Fig. 4A). Although apoptotic cells were not detected in the control cells and the cells treated with $10 \mu \mathrm{M}$ tamoxifen, apoptotic cells were detected among the cells treated with progesterone and the combination of progesterone and tamoxifen. The results showed that progesterone induced apoptosis and DNA fragmentation.

Apoptosis ultimately induces the activation of DNA endonuclease, which cleaves DNA into fragments of approximately 180-200 bp. Agarose gel electrophoresis of DNA isolated from progesterone-treated cells showed the characteristic DNA fragmentation ladder, indicating that progesterone-treated cells had the typical characteristics of apoptosis (Fig. 4B).

Apoptosis mediated by p53 is known to involve transcriptional repression of BCL-2 and activation of BAX. To test whether progesterone-induced apoptosis of PA-1 cells is facilitated by this mechanism, PA-1 cells treated with progesterone were subjected to Western blot analysis with anti-BCL-2 and anti-BAX antibodies. Changes in the levels of BCL-2 or BAX were not observed in cells treated with $100 \mu \mathrm{M}$ of progesterone. Western blot analysis of p53 and p21 proteins showed a time-dependent up-regulation in p53 and p21 proteins. After incubation for $24 \mathrm{~h}$, the intensities of the p53 and p 21 bands reached their peaks (Fig. 5A).

To further explore the detailed molecular processes of progesterone-induced apoptosis, the expression of caspase-3, PARP, and cytochrome c was evaluated in progesteronetreated cells. Caspase- 3 is an effector caspase that is critical in many apoptotic pathways. When caspase- 3 is activated, it is cleaved into fragments of 11 and $20 \mathrm{kDa}$. Activated caspase- 3 cleaves several key enzymes that are required for normal cell maintenance, including a DNA repair enzyme PARP (14). Western blot analysis of PARP showed that PARP is cleaved from its intact form $(116 \mathrm{kDa})$ into fragments of 85 and $25 \mathrm{kDa}$. Western blot analysis also showed decreased intensity of the caspase-3 band after progesterone treatment (Fig. 5A). This result suggests that progesterone-induced apoptosis of PA-1 cells involves caspase-3-mediated apoptosis.

To examine the involvement of BAX and cytochrome C, the cell cytosolic and mitochondrial fractions were separated, and the content of BAX protein in each fraction was analyzed by Western blot analysis. The results showed that cytosolic BAX had mostly disappeared after $24 \mathrm{~h}$ and had completely disappeared after $48 \mathrm{~h}$ of progesterone treatment, while the mitochondrial content of BAX increased after $48 \mathrm{~h}$ (Fig. 5B). These results indicate that translocation of BAX from the cytosol to mitochondria mediates progesterone-induced 
A

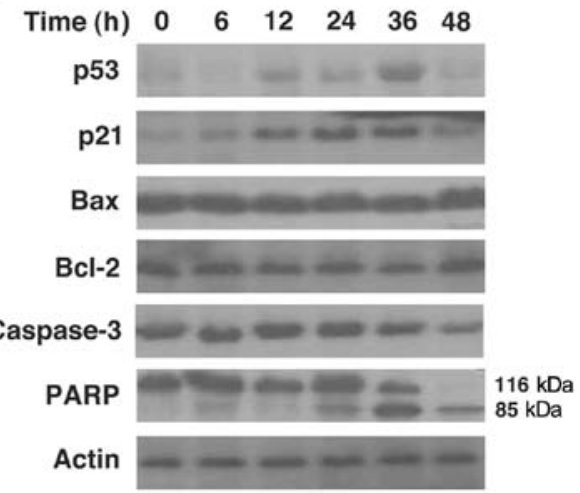

B

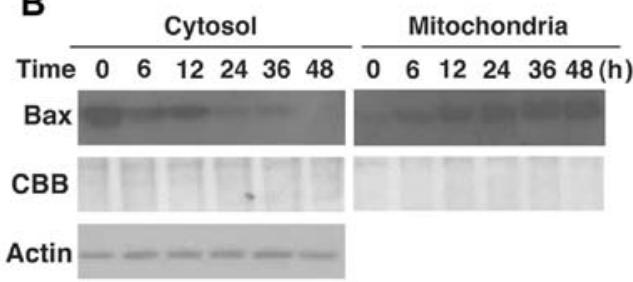

C

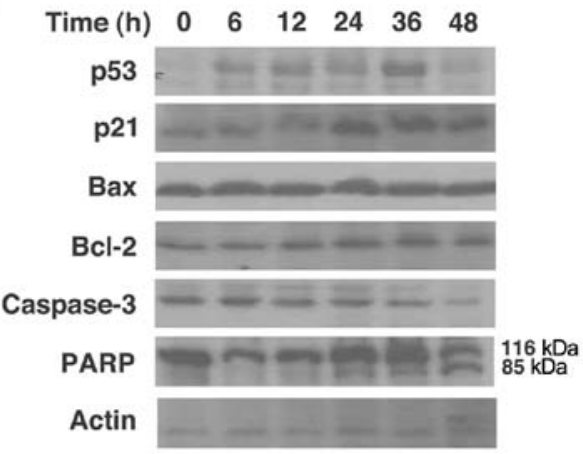

Figure 5. Time course changes in levels of apoptosis-related proteins during progesterone or progesterone/tamoxifen-treated PA-1 cells. (A) PA-1 cells were treated with progesterone $(100 \mu \mathrm{M})$ for $0,6,12,24,36$ and $48 \mathrm{~h}$ and harvested by trypsinization. Cell lysates were subjected to Western blot analysis using anti-p53, anti-p21, anti-BCL-2, anti-BAX, anti-caspase 3 , anti-PARP and anti-actin antibodies. Actin was used as an internal control. (B) Cellular localization of BAX was analyzed by subcellular fractionation and Western blot analysis. Cell pellets were fractionated into mitochondria and cytosol by centrifugation as described in 'Materials and methods'. Mitochondrial and cytosolic fractions were analyzed by Western blot analysis using anti-BAX antibody. (C) PA-1 cells were treated with tamoxifen $(10 \mu \mathrm{M})$ and progesterone $(100 \mu \mathrm{M})$ for $0,6,12,24,36$ and $48 \mathrm{~h}$ and harvested by trypsinization. Cell lysates were subjected for Western blot analysis using anti-p53, anti-p21, anti-bcl2, anti-bax, anti-caspase 3, anti-PARP and antiactin antibodies. Actin was used as an internal control. The experiments were repeated 3 times.

apoptosis, presumably through cytochrome $\mathrm{C}$ release from the mitochondria.

Apoptotic mechanisms were also observed after simultaneous treatment with tamoxifen and progesterone. Up-regulation of p53,p21 and p27 proteins was observed, but the levels of BAX and BCL-2 were unchanged. Cleavage of caspase-3 and PARP were confirmed by Western blot analysis (Fig. 5C).

Analysis of tamoxifen-induced cell growth arrest. Molecular changes induced by tamoxifen were analyzed by Western blot analysis. The p53, p21 and p27 protein levels increased

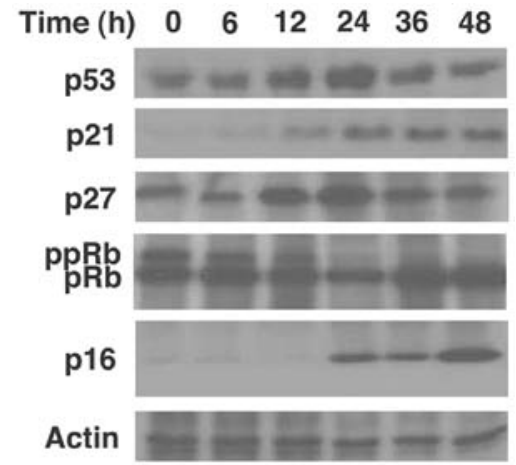

Figure 6. Time course changes in levels of growth arrest-related proteins during tamoxifen-induced growth arrest of PA-1 cells. Cells were treated with tamoxifen $(10 \mu \mathrm{M})$ for $0,6,12,24,36$ and $48 \mathrm{~h}$ and harvested by trypsinization. Cell lysates were prepared as described in 'Materials and methods'. Cell lysates were analyzed for Western blot analysis using anti-p53, anti-p21, anti-p27, anti-p16, anti-Rb and anti-actin antibodies. Actin was used as an internal control. Anti-Rb antibody is able to detect both phosphorylated and dephosphorylated $\mathrm{Rb}$. The experiments were repeated 3 times.

within $24 \mathrm{~h}$ after tamoxifen treatment (Fig. 6). However, the levels of these proteins decreased after $24 \mathrm{~h}$. Increased p16 and dephosphorylated $\mathrm{Rb}$ protein levels were observed $24 \mathrm{~h}$ after tamoxifen treatment. These results suggest that typical $\mathrm{G}_{1}$ arrest is involved in tamoxifen-induced cell cycle arrest.

\section{Discussion}

To investigate the effects of combined progesterone and tamoxifen treatment on ovarian carcinoma, the growth and death of epithelial ovarian cancer cells with wild-type p53 were tested. Progesterone has been reported to promote apoptosis in ovarian carcinoma cells (14) in a p53-dependent manner (15). Tamoxifen causes cell cycle arrest $\left(\mathrm{G}_{0} / \mathrm{G}_{1}\right.$ arrest with up-regulation of both p21 and p27 in susceptible estrogen receptor-positive breast cancer cells (13). However, whether combined treatment with progesterone and tamoxifen has synergistic anti-cancer effects has also not been investigated. In this study, we demonstrated that progesterone treatment of ovarian carcinoma cells triggers apoptosis and tamoxifen treatment induces growth arrest at $\mathrm{G}_{1}$. Combined treatment induced apoptosis similar to that induced by progesterone alone and had no synergistic effect on progesterone treatment alone. Flow cytometric analysis showed that progesterone treatment and combined treatment with both hormones induced apoptosis after $48 \mathrm{~h}$ while tamoxifen treatment alone induced mostly $\mathrm{G}_{1}$ arrest (Fig. 3). Furthermore, the TUNEL assay and DNA fragmentation analysis confirmed that progesterone treatment and combined treatment induced apoptosis (Fig. 4). Western blot analysis revealed the digestion of PARP and caspase- 3 in both progesterone treatment and combined treatment (Fig. 5). Tamoxifen treatment resulted in $\mathrm{G}_{1}$ arrestrelated induction of p21 and p16 and dephosphorylation of pRB (Fig. 6). Combined treatment showed no synergistic effect as compared to treatment with progesterone alone. We expected that combined treatment would induce more apoptosis or cell cycle arrest or cause these events to occur at a faster rate than either treatment alone. However, the results showed that this 
did not happen. Currently, we do not have an answer as to why this occurred.

One plausible explanation is the following. It has been proposed that the binding of p53 to specific p53 response elements differs greatly. Low-affinity sites appear to be associated with growth arrest-related genes, while highaffinity sites are more related to proapoptotic genes $(16,17)$. Ubiquitination of p53 in response to mild damage is known to be associated with growth arrest-related genes, and acetylated and phosphorylated p53 proteins activate proapoptotic genes in response to severe damage. In addition, p53-interacting proteins like HZF interact directly with the p53 DNA-binding domain to activate p21 while proapoptotic genes are attenuated. In contrast, CAS is associated with p53 on the promoters of several proapoptotic genes. This relieves the inhibitory H3K27 methylation within the transcribed region of those genes, thereby increasing their transcription and facilitating apoptosis $(18,19)$. Therefore, tamoxifen treatment appears to cause mild damage in which p53 induces growth arrest whereas progesterone treatment causes severe damage, which results in apoptosis. Combined treatment seems to induce a severe form of damage, resulting in apoptosis similar to the case of progesterone treatment.

We still do not know the detailed mechanism of how p53 decides between growth arrest and apoptosis in PA-1 cells subjected to these treatments. Combined treatment is used in many therapeutic cancer regimes since it sometimes results in synergistic effects on cancer. Some cell death-inducing agents that induce the death of cancer cells via different pathways will exert a synergistic effect. Even combined treatment with apoptosis-inducing agents will be advantageous if the two agents involve different apoptosis pathways. However, the combination of an anti-cancer medicine that induces growth arrest and another that induces apoptosis may not be recommended as the combination will not have an advantageous effect. Further detailed characterization of the mechanisms of action of these medicines in p53-deleted or p53-mutated ovarian cancer cells may provide a better understanding of these treatment methods.

\section{Acknowledgements}

This study was supported by Priority Research Centers Program through the National Research Foundation of Korea (NRF) funded by the Ministry of Education, Science and Technology (2010-0029642).

\section{References}

1. Caldas C and McGuire WP III: Paclitaxel (Taxol) therapy in ovarian carcinoma. Semin Oncol 20 (Suppl 3): S50-S55, 1993.

2. Long RT and Evans AM: Diethylstilbestrol as a chemotherapeutic agent for ovarian carcinoma. Mol Med 60: 1125-1127, 1963.

3. Slotman BJ and Rao BR: Ovarian cancer: etiology, diagnosis, prognosis, surgery, radiotherapy, chemotherapy and endocrine therapy. Anticancer Res 8: 417-434, 1988.
4. Riman T, Persson I and Nilsson S: Hormonal aspects of epithelial ovarian cancer: review of epidemiological evidence. Clin Endocrinol 49: 695-707, 1998.

5. Risch HA: Hormonal etiology of epithelial ovarian cancer, with a hypothesis concerning the role of androgens and progesterone. J Natl Cancer Inst 90: 1774-1786, 1998.

6. Ivarsson K, Sundfeldt K, Brannstrom M and Janson PO: Production of steroids by human ovarian surface epithelial cells in culture: Possible role of progesterone as growth inhibitor. Gynecol Oncol 82: 116-121, 2001.

7. van der Vange N, Greggi S, Burger CW, Kenemans $\mathrm{P}$ and Vermorken JB: Experience with hormonal therapy in advanced epithelial ovarian cancer. Acta Oncol 34: 813-820, 1995.

8. Myers AM, Moore GE and Major FJ: Advanced ovarian carcinoma: response to antiestrogen therapy. Cancer 48: 2368-2370, 1981.

9. Marth C, Daxenbichler G, Buehring GC, Hofstädter F and Dapunt O: Inhibition of the estradiol-induced growth of cultured human breast cancer cells by the anti-estrogens tamoxifen, desmethyl-tamoxifen, 4-hydroxy-tamoxifen and enclomiphene. Biochem Pharmacol 33: 3951-3956, 1984.

10. Beecham J, Blessing J, Creasman W and Hatch K: The role of tamoxifen as second line therapy in advanced ovarian cancers evaluated for receptor status and tumor grade. Proc Int Gynecol Cancer Soc 1: 117, 1987.

11. Weiner SA, Alberts DS, Surwit EA, Davis J and Grosso D: Tamoxifen therapy in recurrent epithelial ovarian carcinoma. Gynecol Oncol 27: 208-213, 1987.

12. Munstedt K, Steen J, Knauf AG, Buch T, von Georgi R and Franke FE: Steroid hormone receptors and long term survival in invasive ovarian cancer. Cancer 89: 1783-1791, 2000.

13. Cariou S, Donovan JCH, Flanagan WM, Milic A, Bhattacharya N and Slingerland JM: Down-regulation of p21WAF1/CIP1 or p27Kip1 abrogates antiestrogen-mediated cell cycle arrest in human breast cancer cells. Proc Natl Acad Sci USA 97: 90429046, 2000

14. Bu SZ, Yin DL, Ren XH, Jiang LZ, Wu ZJ, Gao QR and Pei G: Progesterone induces apoptosis and up-regulation of p53 expression in human ovarian carcinoma cell lines. Cancer 15: 1944-1950, 1997.

15. Yu S, Lee M, Shin S and Park JS: Apoptosis induced by progesterone in human ovarian cancer cell line SNU-840. J Cell Biochem 82: 445-451, 2001.

16. Inga A, Storici F, Darden TA and Resnick MA: Differential transactivation by the p53 transcription factor is highly dependent on p53 level and promoter target sequence. Mol Cell Biol 22: 8612$8625,2002$.

17. Laptenko $\mathrm{O}$ and Prives C: Transcriptional regulation by $\mathrm{p} 53$ : one protein, many possibilities. Cell Death Differ 13: 951-961, 2006.

18. Das S, Raj L, Zhao B, Kimura Y, Bernstein A, Aaronson SA and Lee SW: Hzf determines cell survival upon genotoxic stress by modulating p53 transactivation. Cell 130: 624-637, 2007.

19. Ewings KE and Ryan KM: Hzf and hCAS/CSE1L: making the right choice in p53-mediated tumour suppression. Cell Res 17: 829-831, 2007. 